\title{
Use of magnetic resonance imaging in the diagnosis of a tibial fissure fracture in a four-year-old American Quarter Horse gelding: A clinical case ${ }^{11}$
}

\author{
MAGDALENA SZKLARZ, MACIEJ JANECZEK, ANJA KASPAREK*, MARTIN WASELAU*
}

\author{
Department of Animal Physiology and Biostructure, Faculty of Veterinary Medicine, \\ Wrocław University of Environmental and Life Sciences, 50-375 Wrocław, Poland \\ *Equine Hospital Aschheim, Equine Diagnostic Center Munich, 85609 Aschheim, Germany
}

Szklarz M., Janeczek M., Kasparek A., Waselau M.

\section{Use of magnetic resonance imaging in the diagnosis of a tibial fissure fracture} in a four-year-old American Quarter Horse gelding: A clinical case

\section{Summary}

The summary describes a clinical case of a four-year-old American Quarter Horse gelding presented for evaluation of a grade 2-3 (2-3/5) lameness of the right hind limb. The patient underwent a thorough clinical and orthopaedic examination including limb flexion tests and diagnostic anaesthesia. Intra-articular anaesthesia of the stifle joint was impossible because of the uncooperative behaviour of the horse. However, provocation tests and radiographs proved diagnostically inconclusive. Therefore, magnetic resonance imaging of the right stifle was performed, revealing a tibial fissure fracture. The result was diagnostic and surprising, considering the degree and chronic nature of the lameness. Based on the findings of magnetic resonance imaging, the horse underwent surgery by the locking compression technique to restore full limb function. All implants were removed six months after surgery. The gelding returned to training without any signs of lameness.

Keywords: equine, stifle lameness, MRI, fissure fracture, tibia

The present case of an American Quarter Horse (AQH) gelding with handling problems and a history of lameness underlines the importance of advanced diagnostic imaging in equine orthopaedics. In equine ambulatory practices, lameness is usually evaluated by adspection, palpation and provocative tests, such as flexion tests, followed by both regional and/or joint analgesia, as well as radiography and an ultrasonographic examination. However, advanced imaging techniques, such as scintigraphy, CT or MRI, may be required. All of these imaging modalities can be carried out either under general anaesthesia or on a standing horse. Some horses are unwilling to cooperate during clinical examination and require the administration of sedatives, which may affect the examination results. Occasionally, a history of a recent trauma and a complete medical history may assist in identifying the possible region and source of pain. The veterinarians are responsible for all the personnel assisting in the clinical

The research was supported by mission-related research and development funds allocated to the Faculty of Veterinary Medicine, Wrocław University of Environmental and Life Sciences.

The publication was supported by the Wrocław Centre for Biotechnology and the 2014-2018 Leading National Research Centre (KNOW) programme. and orthopaedic examination of an anxious horse. If the source of lameness cannot be determined by standard radiography or ultrasonography, MRI should be performed. The value of this imaging technique has often been recognized $(9,20)$. Along with radiography, MRI should be considered as an additional imaging tool in the diagnosis of equine lameness $(2,12)$. The MRI examination is safe for both the patient and the veterinarian, and it is an imaging modality that facilitates the diagnosis of unclear cases, the formulation of a prognosis or the prediction of recovery.

\section{Case description}

Case history. A 3.5-year-old horse was purchased as a pleasure horse. His exercise programme included lunging and light work under the saddle 4-5 times a week. Four months later the gelding presented with persistent lameness of the right hind limb without a history of recent trauma. The patient showed a grade $2 / 5$ right hind lameness in trot and canter. The horse was observed and palpated, revealing no signs of local edemas or crepitations in the distal part of the limb. However, palpation revealed an effused right femoropatellar joint. Left-hand lunging on soft ground slightly increased the degree of lameness. 


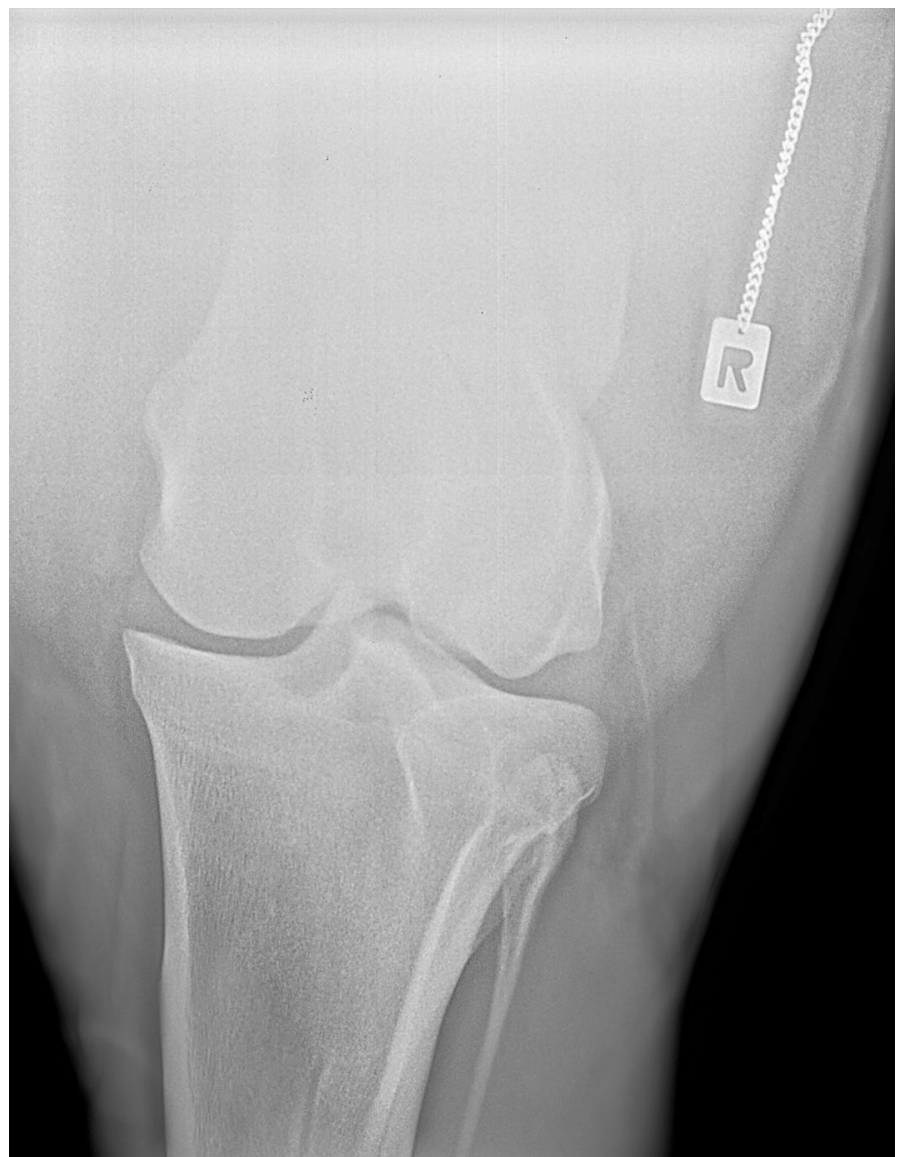

Fig. 1. Anterio-posterior radiograph of the right stifle

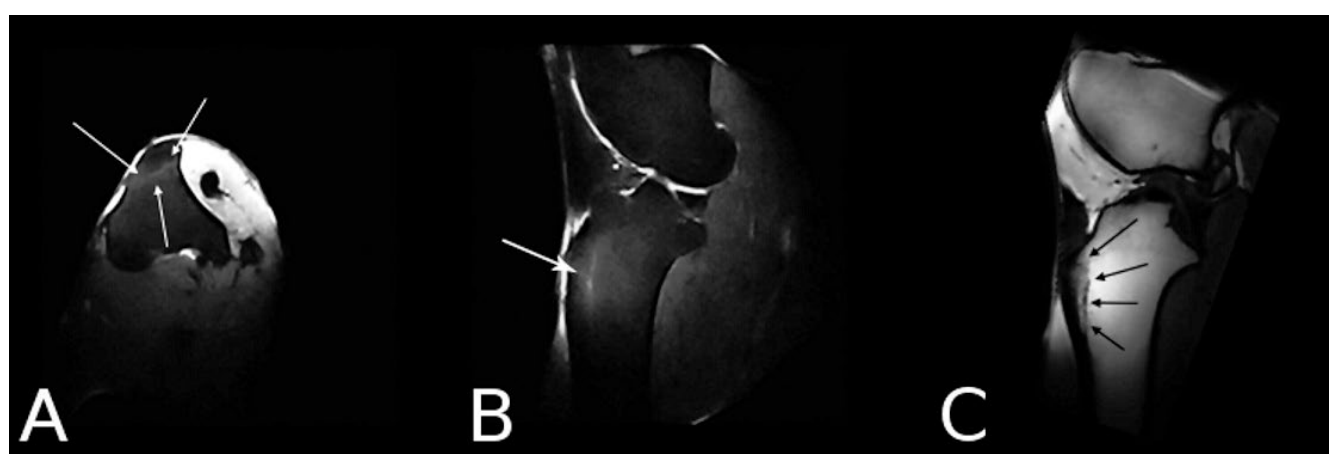

Fig. 2. MRI scans. Visualisation of the fissure fracture

The horse did not tolerate the palpation procedure, flexion tests and injections. Therefore, NSAIDs ( $4 \mathrm{mg} / \mathrm{kg} \mathrm{BW}$ PO; Phenylbutazon ${ }^{\circledR}$, CP-Pharma) were administered orally, and the owner was advised to rest the patient in a box for two weeks.

Re-examination revealed no clinical improvement of the lameness ten days later. Further diagnostic tests, including local anaesthesia and radiographs, were proposed. However, none of the procedures could have been safely performed under field conditions without strong sedation. The owner chose to transport the gelding to a clinic for further diagnostic lameness examination.

Clinical findings. Twelve days after the onset of lameness, the patient presented at the hospital showing a spontaneous grade 2- (2-3)/5 lameness of the right hind limb in trot. Adspection alone did not show any significant abnormalities. Further examinations of all four hooves carried out with hoof testers were negative, and no signs of pain or pulsation were observed. The palpation of the right hind limb confirmed an enlarged volume of the femoropatellar joint. Next, flexion tests were performed. Except for the right hind limb, the results were negative, and there was no deterioration in the limb movement. In the right hind limb, the distal plantar joints test was questionable, as the patient showed increased lameness over the course of several steps, while the upper limb flexion test was positive, indicating a potential tarsal or stifle problem. Unlike in the standard examination protocol, radiographs of the fetlock, tarsus and stifle were taken, but proved inconclusive (Fig. 1). In view of the handling problems and previous flexion test results, fetlock joint anaesthesia was performed instead of stifle joint anaesthesia, because of the high risk of injury to both the patient and the veterinarian associated with the latter procedure. Acepromazine was administered orally at a low dose $\left(0.5 \mathrm{mg} / \mathrm{kg} \mathrm{BW}\right.$; Vetranquil $1 \%$ Granulat $^{\circledR}$, Ceva) prior to the procedure. However, the intra-articular fetlock joint anesthesia (12 ml Meaverin ${ }^{\circledR}$ - Actavis $2 \%$, Actavis) was negative. Because of the inconclusive results of the examinations, the clinical condition of the gelding, the effusion of the femoropatellar joint and the positive flexion test, an MRI examination of the right stifle was planned. The radiographs did not produce significant findings, but suggested possible lesions in the soft tissue of the stifle (12). An ultrasound examination was not performed because of safety concerns due to the uncooperative behaviour of the animal.

The MRI examination was performed under general anaesthesia (9), using an Esaote $0.3 \mathrm{~T}$ Rotating Vet MR Grande XL MRI system. General anaesthesia was induced with diazepam $(0.02 \mathrm{mg} / \mathrm{kg}$ BW; Diazepam-ratiopharm ${ }^{\circledR}$, Ratiopharm) and ketamine $\left(2.2 \mathrm{mg} / \mathrm{kg} \mathrm{BW}\right.$; Anesketin ${ }^{\circledR}$, Albrecht) administered intravenously and maintained with isoflurane (IsoFlo $\left.{ }^{\circledR}, \mathrm{Abbott}\right)$ in a semiclosed-circuit inhalation system. The anaesthesia was preceded by intravenous sedation with xylazine $(1.1 \mathrm{mg} /$ kg BW; Xylariem ${ }^{\circledR}$, Ecuphar) and butorphanol $(10 \mu \mathrm{g} / \mathrm{kg}$ BW; Alvegesic ${ }^{\circledR}$, CP-Pharma). The patient was placed in dorso-lateral recumbency with the right hind limb extended vertically. Routinely, Proton Density (PD, $4 \mathrm{~mm}$ slides),

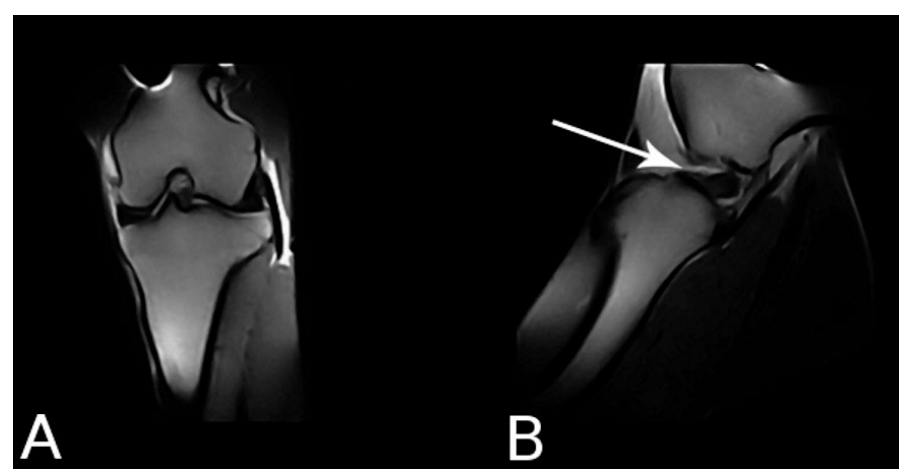

Fig. 3. A. An MR image of the right stifle in the dorsal plane, meniscal degeneration; B. MRI, desmopathy of the cranial cruciate ligament 


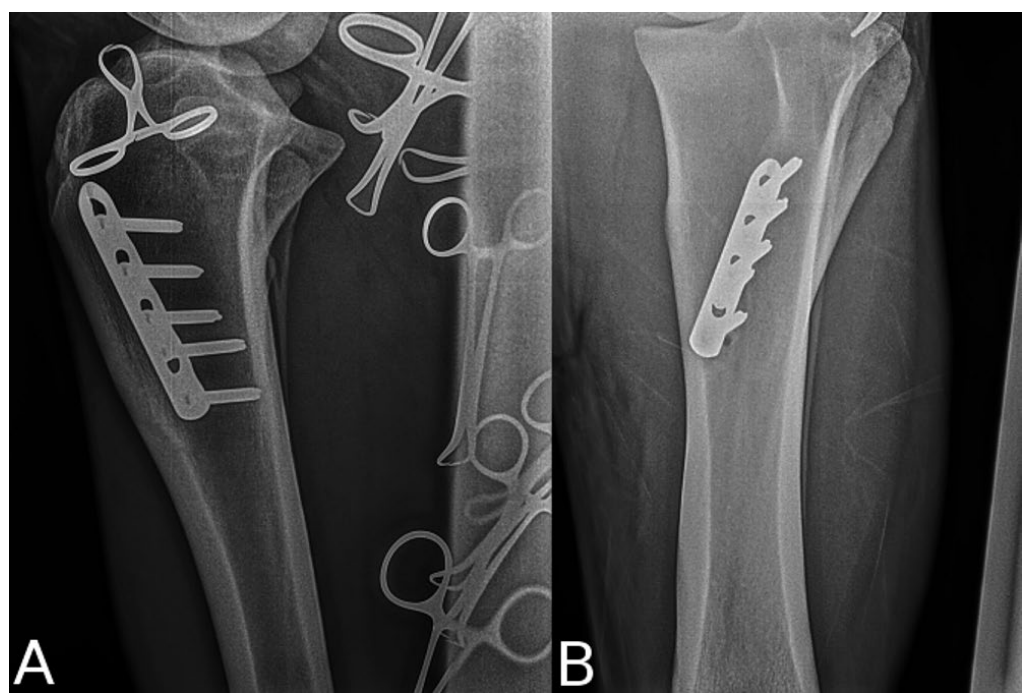

Fig. 4. Intraoperative radiographs
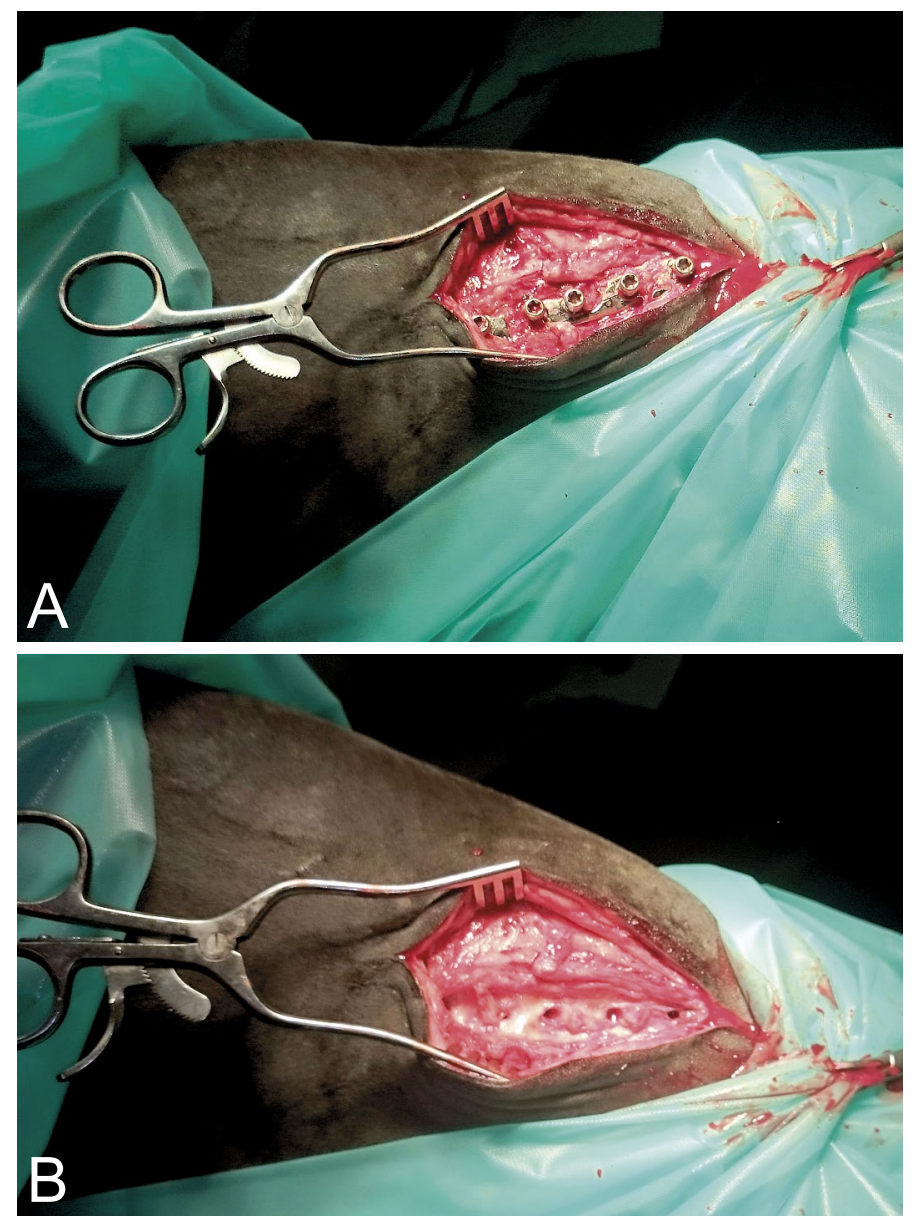

Fig. 5. Intraoperative view. Implants removal

T1- (1 mm slides), T2- (4 mm slides) and STIR-weighted sequences ( $5 \mathrm{~mm}$ slides) were obtained in frontal, sagittal and axial planes followed by $3-\mathrm{D}$ reconstruction. The procedure lasted 70 minutes. The main MRI finding was a proximal tibia fissure fracture (Fig. 2 A, B, C) starting craniomedially in the metaphysis and extending distally. Furthermore, degenerative changes of both menisci (Fig. $3 \mathrm{~A}$ ) as well as desmopathy of the cranial cruciate ligament (Fig. 3B) and cartilage lesions were diagnosed.

The gelding underwent surgery to stabilize the fissure, accelerate the remodelling of the bone and restore full limb function (Fig. 4A, B). This was accomplished by the locking compression technique $(3,4)$. Surgery was performed using a craniomedial approach with one incision starting medially at the level of the distal tibial tuberosity on the limb extended vertically with the patient placed in dorsal recumbency. General anaesthesia was maintained using the same protocol as for MRI. The surgical incision was closed in one layer with absorbable synthetic monofilament suture material (Monosyn ${ }^{\circledR}$, B. Braun). An absorbable suture was used for a stent bandage in order to avoid potential trauma caused by a panic attack of the horse during suture removal.

After the operation, the patient spent the first eight weeks cross-tied in a box to minimize movement and avoid fatal recumbency. The use of a supportive sling system was advised, but rejected due to the character of the patient. After eight weeks, the gelding was hand-walked for two minutes. This time was slowly increased every week. Twelve weeks after surgery, the patient was discharged from the hospital in good condition. After another four weeks (four months after surgery), the gelding underwent a control orthopedic examination, which did not reveal any signs of pain or lameness when walking or trotting. In view of the examination results, it was decided to prepare a small individual paddock for the horse and to start light exercise at the lunge.

The implants were removed under short general anaesthesia six months after surgery (Fig. 5 A, B). The gelding returned to training without any signs of lameness.

\section{Results and discussion}

The current case report summarises clinical findings that could not have been obtained without advanced imaging procedures (20). It is clear that a detailed history provided by the owner is crucial for accurate diagnosis and treatment. Given that the gelding had no history of trauma, tibial injury should also be considered in stifle lameness in horses. A tibial fracture can occur secondary to external trauma or a fall as well as sudden pivoting while running on a pasture. Young horses are particularly prone to physeal or crest fractures, including a tibial tuberosity fracture, as a result of a partial rotation of the stifle during a sudden movement and forces connected with quadriceps muscle attachments to the tibial tuberosity $(13,19)$. The authors are specialised in stifle MRI, which is a method of choice in diagnosing deep soft-tissue damage in horses $(9,10)$. According to the MRI findings, the fracture could have resulted from a repetitive tibial stress, since no signs of an acute trauma were revealed. This hypothesis is supported by the repeated inconclusive radiography performed at the time, in which hairline fracture changes are recognisable $(6,20)$. However, degenerative changes in the articular cartilage, both menisci and the cranial cruciate ligament, as seen on MRI, were regarded as a chronic disorder, not necessarily related to the fissure. 
Even though conservative management is thought to be successful in most patients with an incomplete tibial fissure, surgical treatment aimed at stabilizing the fracture, accelerating the remodelling of the bone tissue and reducing the convalescence time was chosen because of the MRI results and the risk associated with recovering from general anaesthesia. It seems that conservative treatment by stall confinement with a potential support system (19) should no longer be a method of choice in tibial fracture management in equine patients $(2,14)$. Spiral fissure fractures are an exception, as there is a risk of complete fracture (7) and the prognosis is unfavourable. In such cases, the use of a sling and restrictive stall confinement are the methods of choice.

In equine practice, fissure fractures of the tibia are relatively rare post-traumatic fractures of the proximal limb. (6). On the other hand, the forces exerted on the tibial bone are enormous, predisposing it to stress fractures in racehorses with repeated micro-injuries $(5,15,17)$. If stress fractures are not diagnosed and treated correctly, they may lead to complete catastrophic fracture $(7,11)$. The prognosis can range from poor or guarded to good, depending on the clinical findings and anatomical conditions $(3,6,19)$. Unlike the favourable prognosis for physeal non-displaced fractures, the prognosis for metaphyseal incomplete fractures is guarded to poor (19). Even if a fracture appears to be stable and susceptible to conservative treatment by stall confinement, the risk of a complete fracture should always be considered while choosing the treatment method $(1,8,19)$. A splint is not recommended for anaesthesia recovery, hence it is advisable to assist the patient if there is no possibility of using a recovery pool (19).

Making a diagnosis based on the radiographic appearance of the fracture line is not always feasible, particularly after an acute trauma $(16,20)$. Since fracture lines are not recognizable by radiography until a few weeks after the initial trauma, fractures should always be considered in horses with severe persistent lameness without any conclusive radiographic findings (6). Therefore, it is advisable to use advanced imaging techniques when diagnosing a patient with lameness of unknown origin $(15,20)$. Since scintigraphy does not permit the recognition and description of the fracture, it is increasingly being replaced by MRI, which is considered to be more accurate (16). In addition to financial constraints, which are less significant in valuable sport horses, the main limitation for MRI is general anaesthesia and dorsal recumbency, as standing MRI scanners can only be used to examine the distal part of the limb. During recovery from general anaesthesia after MRI, an incomplete fracture may become a complete one. Therefore, according to general anaesthesia techniques in horses, surgery should ideally be performed directly after the MRI scanning procedure, thus prolonging the duration of anaesthesia, but eliminating the risk of additional recovery.

MRI usage in horses has already been described as a promising technique in diagnosing third metacarpal bone stress fractures and as a comparative model for standard MRI usage in human medicine stress fracture diagnosis (20). As a result of the development of MRI in human medicine, the operative and imagery techniques have been increasingly implemented in veterinary medicine $(2,18)$. Therefore, a routine MRI examination, if available, should be considered in the diagnosis and treatment of equine patients.

\section{References}

1. Auer J. A.: Principles of fracture treatment, [in:] Auer J. A., Stick J. A. (eds.) Equine Surgery. Saunders Elsevier, St. Louis, Missouri 2006, p. 1000-1030.

2. Auer J. A., Grainger D. W.: Fracture management in horses: Where have we been and where are we going? Vet. J. 2015, 206, 5-14.

3. Bramlage L. R.: Tibia, [in:] Auer J. A., Stick J. A. (eds.): Equine Surgery. Saunders Elsevier, St. Louis, Missouri 2006, p. 1308-1315.

4. Bramlage L. R., Hanes G. E.: Internal fixation of a tibial fracture in an adult horse. J. Am. Vet. Med. Assoc. 1982, 180, 1090-1094.

5. Currey J. D.: How well are bones designed to resist fracture? J. Bone. Miner. Res. 2003, 18, 591-598.

6. Derungs S., Fuerst A., Haas C., Geissbuehler U., Auer J. A.: Fissure fractures of the radius and tibia in 23 horses: a retrospective study. Equine Vet. Educ. 2001, 13, 313-318.

7. Fuerst A., Oswald S. E., Jaeggin S., Piskoty G., Michel S., Auer J. A.: Fracture configurations of the equine radius and tibia after a simulated kick. Vet. Comp. Orthop. Traumatol. 2008, 21, 49-58.

8. Harrison L. J., May S. A., Richardson J. D., Mills G., Dixon P.: Conservative treatment of an incomplete longbone fracture of a hindlimb of four horses. Vet. Rec. 1991, 129, 133-136.

9. Holcombe S. J., Bertone A. L., Biller D. S., Haider V.: Magnetic Resonance Imaging of the Equine Stifle. Vet. Radiol. Ultrasound 1995, 36, 119-125.

10. Kasparek A., Waselau M., Bracher B., Szklarz M.: Diagnostyka kulawizny u konia rezonansem magnetycznym - przypadek kliniczny. Mag. Wet. 2015, 214, 220-227.

11. Kulesza O., Kaczorowski M., Turek B.: Złamania zmęczeniowe u koni. Życie Wet. 2005, 80, 750-755.

12. Martinelli M. J., Rantanen N. W.: Clinical commentary. Lameness originating from the equine stifle joint. A diagnostic challange. Equine Vet. Educ. 2009, 21, 648-651.

13. Maulet B. E. B., Mayhew I. G., Jones E., Booth T. M.: Radiographic anatomy of the soft tissue attachments of the equine stifle. Equine Vet. J. 2005, 37, 530-535.

14. Nunamaker D. M.: On Bone and Fracture Treatment in the Horse. $48^{\text {th }}$ Annual Convention of the American Association of Equine Practitioners, Orlando, Florida 2002, 48, p. 90-101.

15. O'Sullivan Ch. B., Lumsden J. M.: Stress fractures of the tibia and humerus in Thoroughbred racehorses: 99 cases (1992-2000). J. Am. Vet. Med. Assoc. 2003, 222, 491-498.

16. Ramzan P. H. L., Newton J. R., Shepherd M. C., Head M. J.: The application of a scintigraphic grading system to equine tibial stress fractures: 42 cases. Equine Vet. J. 2003, 35, 382-388.

17. Ruggles A. J., Moore R. M., Bertione A. L., Schneider R. K., Bailey M. Q.: Tibial stress fractures in racing standardbreds: 13 cases (1989-1993). J Am. Vet. Med. Assoc. 1996, 209, 634-637.

18. Schramme M., Redding W. R.: Magnetic Resonance Imaging, [in:] Baxter G. M. (ed.): Adams and Stashak's Lameness in Horses. Wiley-Blackwell, Ames, Iowa 2012, p. 416-448.

19. Sullins K. E.: The Tibia, [in:] Baxter G. M. (ed.): Adams and Stashak's Lameness in Horses. Wiley-Blackwell, Ames, Iowa 2012, p. 770-780.

20. Tapprest J., Audigie F., Radier C., Anglade M. C., Voisin M. C., Foucher N., Collobert-Laugier C., Mathieu D., Denoix J. M.: Magnetic Resonance Imaging for the diagnosis of the stress fractures in a horse. Vet. Radiol. Ultrasound $2003,44,438-442$

Corresponding author: Magdalena Szklarz, PhD student, ul. Kożuchowska 1/3, 51-631 Wroclaw, Poland; e-mail: magdalena.szklarz@upwr.edu.pl 